\title{
Flight-Deck Strategies and Outcomes When Flying Schedule-Matching Descents
}

\author{
John Kaneshige ${ }^{1}$ \\ NASA Ames Research Center, Moffett Field, CA, 94035 \\ Shivanjli Sharma ${ }^{2}$ \\ Stinger Ghaffarian Technologies, NASA Ames Research Center, Moffett Field, CA, 94035 \\ Lynne Martin ${ }^{3}$ \\ San Jose State University, NASA Ames Research Center, Moffett Field, CA, 94035 \\ Sandra Lozito ${ }^{4}$ \\ NASA Ames Research Center, Moffett Field, CA, 94035 \\ and \\ Victoria Dulchinos ${ }^{5}$ \\ San Jose State University, NASA Ames Research Center, Moffett Field, CA 94035
}

\begin{abstract}
Recent studies at NASA Ames Research Center have investigated the development and use of ground-based (air traffic controller) tools to manage and schedule air traffic in future terminal airspace. An exploratory study was undertaken to investigate the impacts that such tools (and concepts) could have on the flight-deck. Ten Boeing 747-400 crews flew eight optimized profile descents in the Los Angeles terminal airspace, while receiving scripted current day and futuristic speed clearances, to ascertain their ability to fly schedulematching descents without prior training. Although the study was exploratory in nature, four variables were manipulated: route constraints, winds, speed changes, and clearance phraseology. Despite flying the same scenarios with the same events and timing, there were significant differences in the time it took crews to fly the approaches. This variation is the product of a number of factors but highlights potential difficulties for scheduling tools that would have to accommodate this amount of natural variation in descent times. The focus of this paper is the examination of the crews' aircraft management strategies and outcomes. This includes potentially problematic human-automation interaction issues that may negatively impact arrival times, speed and altitude constraint compliance, and energy management efficiency.
\end{abstract}

\section{Introduction}

T today's air traffic system, an aircraft flying through a busy terminal area can expect to be given multiple speed 1 changes, altitude level-offs, and/or heading vectors. While these Air Traffic Control (ATC) methods can result in a very safe system, it is often not efficient on a per flight basis. When demand is low, there is more space between aircraft so controllers have the flexibility of descending aircraft along an energy efficient descent profile computed by aircraft Flight Management Systems (FMS). ${ }^{1}$ When demand is high, traffic density often constrains the availability of these nominal profile descents along Standard Terminal Arrival Routes (STARs).

${ }^{1}$ Computer Scientist, Intelligent Systems Division, Mail Stop 269-1, AIAA Senior Member.

${ }^{2}$ Research Engineer, Intelligent Systems Division, Mail Stop 269-1.

${ }^{3}$ Researcher, Human Systems Integration Division, Mail Stop 262-4.

${ }^{4}$ Research Psychologist, Aviation Systems Division, Mail Stop 210-1.

${ }^{5}$ Human Factors Researcher, Aviation Systems Division, Mail Stop 210-1.

1

American Institute of Aeronautics and Astronautics 
The Air Traffic Management (ATM) Technology Demonstration-1 (ATD1) concept was developed by NASA to safely sustain high runway throughput while also enabling fuel-efficient operations. ${ }^{2}$ Research is being undertaken in advanced scheduling capabilities that create schedules at the runway to enable aircraft to fly Optimized Profile Descents (OPDs) along Area Navigation (RNAV) routes. ${ }^{3}$ Aircraft on these descents will be cleared to the runway and then will be able to rely on speed to maneuver as they fly into and through the terminal area. This will allow an aircraft to maintain its place in a tightly packed stream by meeting its scheduled time of arrival (STA). The STA is allocated prior to top-of-descent by a ground-based scheduling system. Assuming en route controllers feed the Terminal Radar Approach Control (TRACON) with a reasonable flow, within certain tolerances of the schedule, TRACON controllers would rely primarily on speed adjustments to bring aircraft through the TRACON. ${ }^{4}$

Controller-Managed Spacing (CMS) research in the Airspace Operations Laboratory has conducted a series of real-time human-in-the-loop simulations to investigate specific controller decision support tools (DSTs) for such operations. ${ }^{5}$ With relatively straight-forward display enhancements, TRACON controllers were able to manage dense arrival flows that followed OPDs along RNAV routes and met runway schedule times without significant increases in their workload. ${ }^{6}$ DSTs also included a speed advisory that was formulated as a speed to fly until a specified downstream waypoint that put the aircraft back on schedule, enabling it to resume published speeds. ${ }^{7}$ One advantage of the CMS clearances, developed to convey such intentions, is that it results in a closed four-dimensional trajectory (4DT) that can be programmed into the FMS.

One set of assumptions within the ATD1 concept, and for the recent relevant research to date, is that these schedule-based RNAV OPDs will have minimal impact on the flight-deck. This encompasses primarily three subassumptions: firstly, that crews will be able to fly these descents and meet the speed instructions issued to them using existing automation; secondly, that they will be able to do this without significant increases to their workload; and thirdly, that no training is required. This flight-deck simulation study was undertaken to explore these assumptions and to examine the crews' workload level and aircraft management strategies. A secondary driver for this study was to explore the variation in, or range of, speeds that are acceptable to a crew throughout their descent, and to inform DSTs regarding where and what limits should be set within the automation. ${ }^{8}$ The advantage of larger speed changes is that DSTs would be able to solve bigger schedule mismatches using speed alone. The disadvantage is that crews would have to manage substantial energy tradeoffs while deviating from the 4DTs computed by their aircraft's FMS for the OPD. To intentionally explore the outer limits of acceptable speed variations, it was determined that twenty percent deviations relative to the published speed profile (or roughly twice the expected control range of the CMS speed advisories), would be used in this study.

A workload and task feasibility analysis as part of this study discovered that some crews could manage large variations in speed instructions and effectively manage the aircraft automation to absorb some of the redistributed/increased workload, but not all. ${ }^{9}$ This paper contains an analysis of the flight-deck aircraft management strategies that were utilized and how they affected the outcomes. This includes identification of potentially problematic human-automation interaction issues that may negatively impact arrival times, speed and altitude constraint compliance, and energy management efficiency.

\section{Flight-Deck Study}

The flight-deck simulation study described in this paper was exploratory and broad, encompassing multiple factors of human-computer interaction, including crew procedures and the use of automation tools. The study consisted of ten Boeing 747-400 crews flying eight OPDs in the Los Angeles terminal airspace. A confederate controller issued scripted voice clearances and addressed queries from the crews. Pseudo pilots controlled traffic in the vicinity for realism. Although the study was exploratory in nature, four variables were manipulated: route constraints, winds, speed changes, and clearance phraseology.

\section{A. Simulation Facilities}

The study was flown in the Boeing 747-400 simulator at the Crew-Vehicle Systems Research Facility at NASA Ames Research Center. ${ }^{10}$ This FAA certified Level D simulator has the same cab configuration as a United Airlines flight-deck (747-422 variant). Additional traffic was generated by the Multi Aircraft Control System (MACS), which also generated the ATC displays. ${ }^{11}$

\section{B. Participants}

Twenty commercial airline pilots (from one of four different carriers) participated as ten two-person crews, with each crew consisting of pilots from the same carrier. All participants were actively flying and type-certified on the B747-400. The average total flight time for the participants was 16,288 hours. 


\section{Routes and Airspace}

Each crew flew eight OPDs through the Los Angeles Terminal Area (SOCAL) into LAX, along two arrival routes that were adapted from the existing SADDE and RIIVR STARs. These routes had been built for prior groundside studies so that aircraft could fly OPDs on RNAV adaptations, giving each route a continuous descent profile from cruise (through the STAR, transition, and approach) to the runway threshold. ${ }^{6}$ The adapted SADDE route (SADDE7) came from the northwest to runway 24R, and the adapted RIIVR route (RIIVR2) came from the east to runway 25L (Fig. 1).

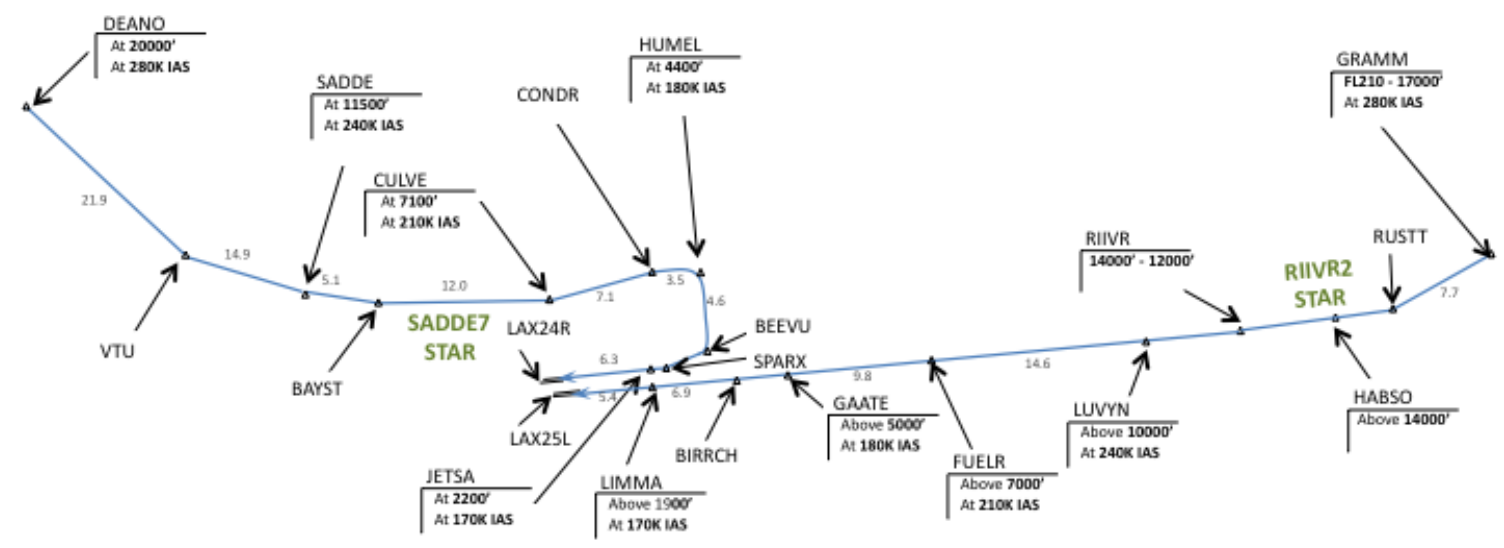

Figure 1. Routes Flown in SoCal Airspace

In the ground automation studies, all the routes were characterized by hard speed and altitude constraints at multiple waypoints through the airspace. The descent angles were designed to be approximately 2.4 degrees (or slightly shallower than the idle descent rate), allowing for more speed control flexibility. However, for this study, these hard constraints were only kept for the SADDE route, which had hard speed and altitude constraints (at DEANO, SADDE, CULVX, HUMEL and JETSA). The RIIVR STAR was partially converted back to a more 'current day' variant of the route, which had window altitude constraints and speed constraints (at GRAMM, LUVYN, FUELR, GAATE and LIMMA). On both routes, the simulator was initialized 135 nautical miles (nm) from the runway (a few miles prior to top-of-descent) at an altitude of $28,000 \mathrm{ft}$ and airspeed of 300 knots.

\section{Winds}

The same forecast winds were used for all runs, beginning at approximately 60 knots at cruise and gradually decreasing to 7 knots at landing (Fig. 2). The wind was always out of $265^{\circ}$, a headwind aligned with the landing runways. The forecast wind profile was entered into the FMS, in order to compute the aircraft's idle descent profile. In half of the runs, the forecast winds matched the simulated winds (i.e., "actual winds"). In the other half of the runs, the simulated winds were ten knots greater than the forecast winds (or "plus winds") between 20,000 ft and $1,500 \mathrm{ft}$.

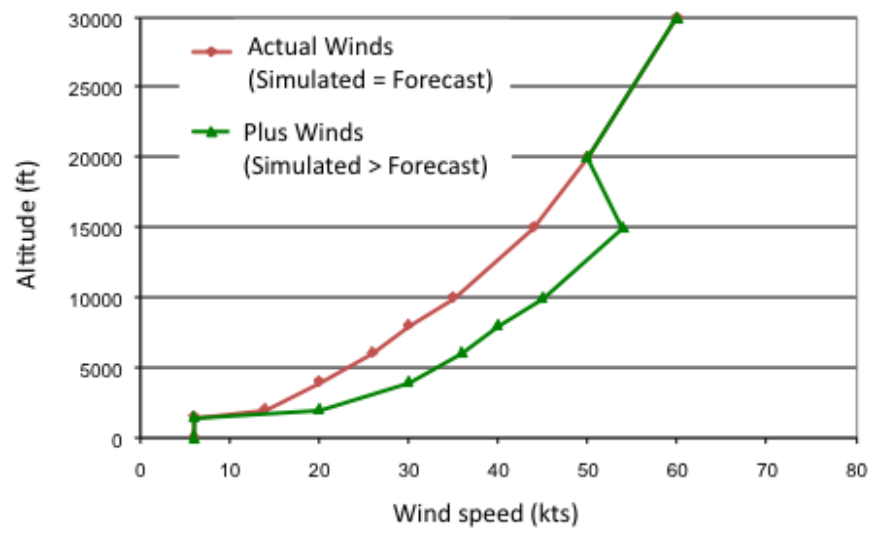

Figure 2. Forecast and Actual Wind Speeds by Altitude 


\section{E. Speed Schemes}

The charted profile speeds were developed to enable continuous descents that would allow aircraft to meet their STAs at the outer marker. ${ }^{7}$ The profile speeds were defined by a series of speed constraints that decelerate aircraft along the route (through $280,240,210,180$, and 160 knots) to the outer marker. This study explored a twenty percent variation from the charted profile speeds (or roughly twice the expected control range of the CMS speed advisories). Crews were asked to fly as fast as 340 knots (approximately $20 \%$ faster than 280 knots) to the first waypoint on the TRACON boundary, and as slow as 160 knots to the outer marker. (160 knots was only $11 \%$ less than 180 knots, but it was considered to be the lowest acceptable speed over these waypoints.)

Two speed schemes were created, each of which had two cycles of speed deviations (Fig. 3). One scheme was a "fast-to-slow" profile, where a faster speed was issued first (i.e., 340 knots), followed by resuming the profile speed (i.e., 280 knots), and then a slower speed was issued (i.e., 220 knots). The second scheme was a "slow-to-fast" profile, where a slower speed was issued first (i.e., 220 knots), followed by resuming the profile speed (i.e., 280 knots), and then a faster speed was issued (i.e., 290 knots). While the control reversals in these speed schemes are unusual, they provide a balance between flying faster and slower than the profile speeds. Additionally, these schemes created a number of points of interest, namely asking for 220 knots above $20,000 \mathrm{ft}$, which is a "dirty" speed for the B-747 (i.e., a speed that is slow enough that crews would normally deploy flaps); and then asking for the same speed for the last $15 \mathrm{~nm}$ before the outer marker, which is relatively fast.

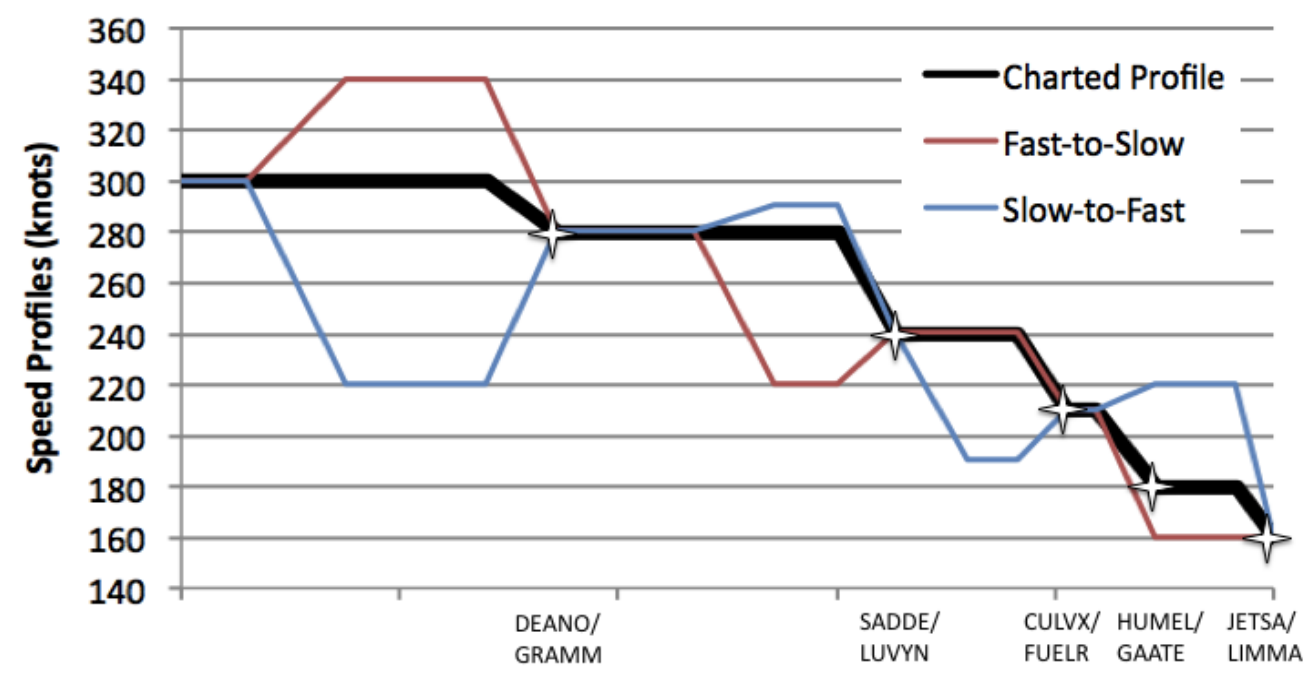

Waypoints on RNAV Route

Figure 3. Speed Schemes

\section{F. Clearance Phraseology}

The phraseology used in the study was manipulated to compare a variant that had been developed in previous ground-side studies with current day phraseology. "Current day" speed clearances were characterized as single-item transmissions that instructed a crew to increase or decrease their speed to a specified number of knots. "Future CMS" speed clearances contained two items. They instructed crews to increase or decrease their speed to a specified number of knots, but also told them where to resume the speed profile (based on the chart constructed for the study) using the phrase "until".

For example, the controller issued a clearance: "Increase speed to 340 until DEANO, then resume published speeds." This clearance instructed the crew to increase their speed from their present speed of 300 knots to 340 knots and to stay at this speed until close to the waypoint DEANO, when they should slow to the speed shown on the chart to cross DEANO at 280 knots.

In the current day condition, the controller issued a first clearance to "increase speed to 340 " followed by a second clearance close to DEANO to "reduce speed to 280." As a result, twice as many speed clearances were issued in the current day phraseology condition compared to the future-CMS condition. While this generated twice as many speed transmissions for the "current day" condition, the clearances in the "future CMS" condition were longer. Although the two conditions differed in their phrasing of the speed clearances, exactly the same increases and reductions were given in both conditions. 


\section{G. Study Design}

The variables for this study were the speed scheme used ("fast-to-slow" or "slow-to-fast"), the phraseology type used ("current day" or "future CMS"), and the type of constraints (i.e., routes) flown (SADDE or RIIVR). This generated a $2 \times 2 \times 2$ matrix ( 2 phraseology $\times 2$ speed scheme $\times 2$ constraint type) that translated to eight scenarios representing each cell of the matrix. These eight scenarios were each presented once to each crew in a semi-random order. Additionally, each crew flew half of their scenarios with simulated winds equaling forecast winds ("actual winds") and the other half with simulated winds being 10 knots greater than forecast winds ("plus winds").

\section{Results}

Of the 80 approaches flown, three were excluded from the data because of simulator artifacts or scenario execution errors (meaning the crew did not receive all of the correct scripted clearances). Of the remaining 77 approaches, the mean and standard deviation of the descent times (from just prior to top-of-descent to the outer marker) for each route and speed scheme combination is presented in Table 1. In general, the large descent time variations can be attributed to the magnitude and frequency of the speed clearances, which resulted in aircraft being in transition between speeds throughout most of the descent.

Table 1. Mean and Standard Deviation of Descent Times

\begin{tabular}{|l|c|c|c|c|}
\hline \multirow{2}{*}{ Scenario } & \multicolumn{3}{|c|}{ Mean Descent Time (mm:ss) + - Standard Deviation (ss) } \\
\cline { 2 - 5 } & \multicolumn{2}{|c|}{ Current Day } & \multicolumn{2}{c|}{ Future CMS } \\
\cline { 2 - 5 } & Actual Winds & Plus Winds & Actual Winds & Plus Winds \\
\hline $\begin{array}{l}\text { SADDE } \\
\text { (Fast-to-Slow) }\end{array}$ & $19: 46+/-17$ & $19: 40+/-13$ & $19: 06+/-09$ & $19: 15+/-21$ \\
\hline $\begin{array}{l}\text { SADDE } \\
\text { (Slow-to-Fast) }\end{array}$ & $19: 45+/-15$ & $19: 23+/-14$ & $19: 29+/-19$ & $19: 37+/-28$ \\
\hline $\begin{array}{l}\text { RIIVR } \\
\text { (Fast-to-Slow) }\end{array}$ & $19: 38+/-17$ & $19: 51+/-09$ & $18: 59+/-22$ & $19: 02+/-32$ \\
\hline $\begin{array}{l}\text { RIIVR } \\
\text { (Slow-to-Fast) }\end{array}$ & $19: 37+/-20$ & $20: 01+/-11$ & $19: 54+/-37$ & $20: 33+/-31$ \\
\hline
\end{tabular}

One observation is that the future CMS phraseology tended to result in shorter descent times (than the current day phraseology) for fast-to-slow speed schemes, and longer descent times for slow-to-fast speed schemes. This is an indication that there were differences between how this type of clearance was interpreted (relative to expectations that were reflected in the timing of the current day phraseology clearances). A second observation is that the future CMS phraseology tended to result in an increased rate of descent time variations (than the current day phraseology). This is an indication that there was confusion regarding how to execute this type of clearance.

The additional plus winds ramp in at approximately $35 \mathrm{~nm}$ into the flight (i.e., below FL200). For the RIIVR route, the plus winds produce an additional headwind that should slightly increase the descent times. This was reflected in the mean descent times resulting from both the current day and future CMS phraseology. For the SADDE route, the plus winds produce an additional tailwind that should slightly decrease the descent times. While this was reflected in the mean descent times resulting from the current day phraseology, it was not reflected in the mean descent times resulting from the future CMS phraseology. This is an indication that the impact of the future CMS phraseology (and/or other factors) dominated the impact of the winds.

Since the speed schemes were designed to provide a balance between flying faster and slower than the profile speeds, the impact that some factors had on descent times needed to be analyzed throughout the descent. Figure 4 contains the standard deviation of the descent times at waypoints along the routes. This leads to a third observation: that the largest rate of increase in descent time variations tended to occur when the aircraft was decelerating to a slower speed. In the slow-to-fast speed schemes (Figs. $4 \mathrm{~b} \& 4 \mathrm{~d}$ ), this initially occurred during the first $40 \mathrm{~nm}$ of the flight, and then continued approximately 60 to $80 \mathrm{~nm}$ into the flight. In the fast-to-slow speed schemes (Figs. 4a \& 4c), this initially occurred approximately 40 to $60 \mathrm{~nm}$ into the flight, and then continued during the last $20 \mathrm{~nm}$ of the flight. This is an indication that energy management considerations were a factor, as crews attempted to decelerate the aircraft while complying with altitude constraints during OPDs. 
SADDE (Fast-to-Slow)

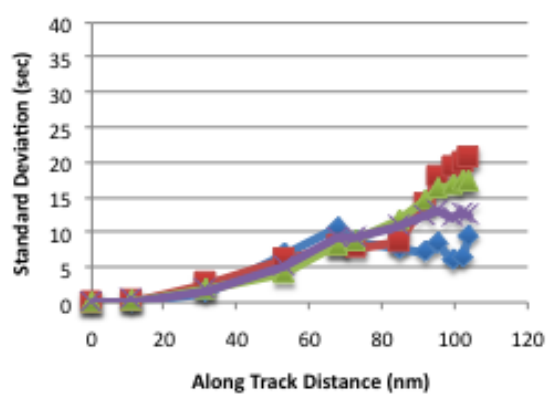

(a)

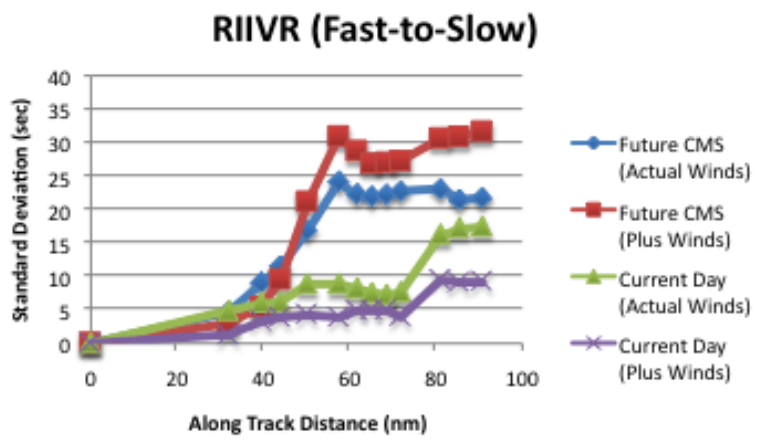

(c)

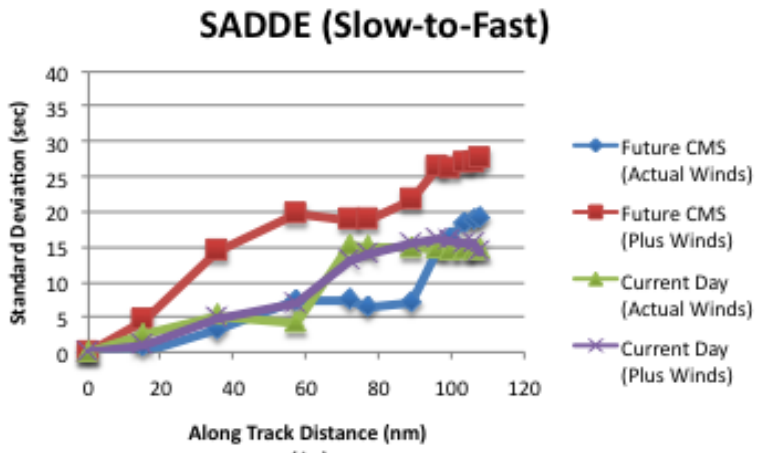

(b)

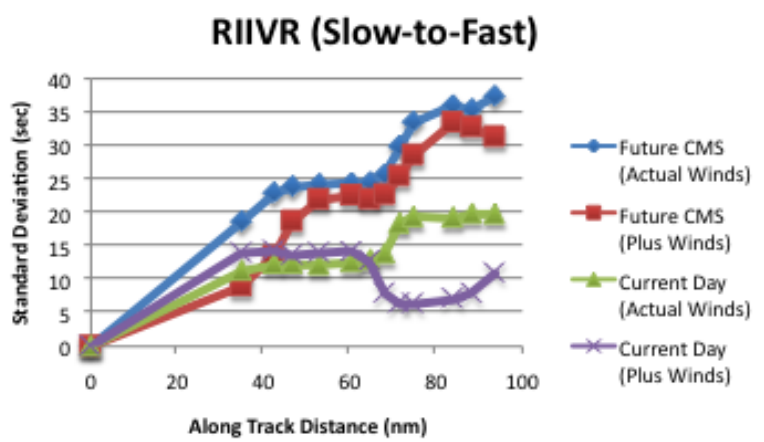

(d)

Figure 4. Standard Deviation of Times at Waypoints

A fourth observation is that the RIIVR route tended to result in larger descent time variations (than the SADDE route). This can be partially attributed to the window altitude constraints in the RIIVR route. While this enabled the aircraft to fly an idle descent profile all the way to the runway, it also resulted in less speed control flexibility than the near-idle descent profile generated by the hard altitude constraints in the SADDE route.

In general, descent time variations can be influenced by many factors that differed across the ten crews who participated. Company procedures, personal flying style, strategies, and understanding of both energy management (in general) and the specific airplane FMS (in particular) all influence how crews interact with flight-deck automation while executing these clearances. The following sections contain an analysis of different aircraft management strategies that were utilized, and how they affected variations in descent times.

\section{A. Future CMS Clearance Execution Strategies}

The primary issue with the future CMS phraseology was that different crews interpreted and executed the conditional clearances in different fashions. Most crews did not resume the published speeds by the "until" waypoint (as expected), instead they waited until they reached the waypoint before starting to resume to the published speeds. Other crews forgot to resume to the published speeds once they crossed the waypoint. As a result, many of these aircraft did not fly the predicted airspeed profiles. An example of this can be seen in Figure 5, which contains the airspeed profiles during the RIIVR route for the fast-to-slow speed scheme with future CMS phraseology. The initial speed clearance was to "increase speed to 340 until GRAMM, then resume published speeds." The published speed restriction at GRAMM was 280 knots. Crew 9 (solid magenta line in Fig. 5) began to decelerate several nautical miles before reaching GRAMM (as expected), so that the aircraft would be at the profile speed of 280 knots when it crossed GRAMM. Crews 2-6 began to decelerate once they reached GRAMM, so the aircraft stayed at a faster speed for a longer period of time (than predicted). Crews 1 and 7 (solid cyan and green lines in Fig. 5) did not begin to decelerate until several nautical miles past GRAMM, and crews 8 and 10 (dashed green and magenta lines in Fig. 5) never resumed published speeds even after they passed GRAMM (and only started to decelerate after they received the next speed clearance). 


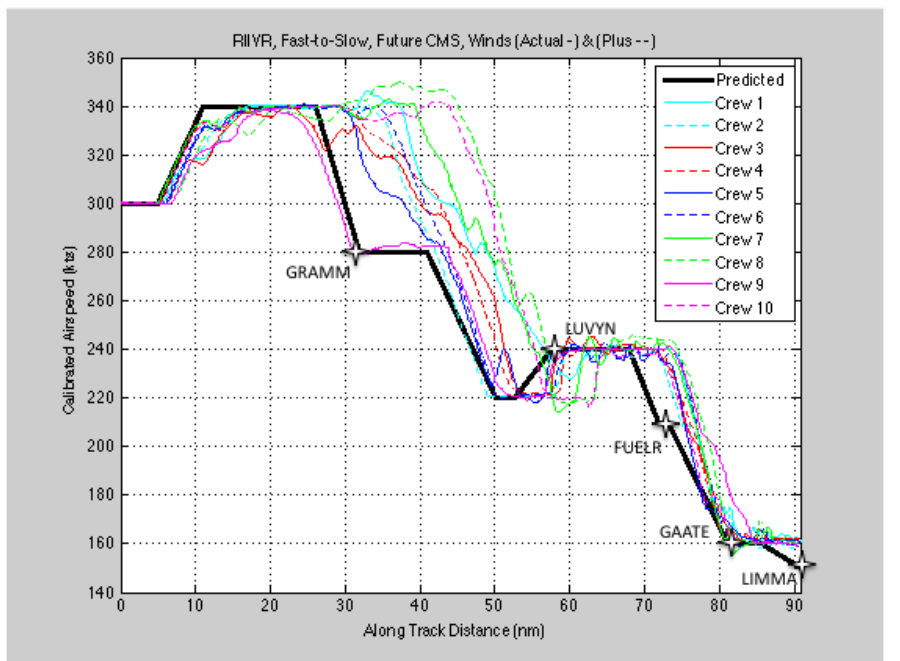

Figure 5. Airspeed Profiles (RIIVR, Fast-to-Slow, Future CMS)

Crews employed different methods of using the automation to execute the future CMS clearances. Most crews entered the commanded speed into the Mode Control Panel (MCP) to override the selected speed in the FMS. This mode is referred to as MCP Speed Intervention, and causes the Vertical Navigation (VNAV) function to switch from flying the vertical path (or VNAV PTH) to capturing and flying the commanded speed (or VNAV SPD). Upon reaching the "until" waypoint, crews would resume to the profile speed by either entering it into the MCP or disengaging MCP SPD Intervention to fly the profile speed (already programmed in the FMS). A couple of crews even highlighted the "until" waypoint (by selecting it in the FIX page of the FMS) to serve as a reminder when to resume to the profile speed.

Some crews (e.g., crew 9 in Fig. 5) entered the commanded speed (e.g., 340 knots) into the FMS, and allowed the aircraft to fly the recalculated vertical path in VNAV PTH. This had the advantage of automatically resuming profile speeds upon reaching the "until" waypoint (i.e., GRAMM) without requiring any actions by the crew. However, this technique encountered an issue when the profile speed was faster than the commanded speed. Since the FMS treats descent speed constraints as AT OR BELOW constraints, the FMS would not accelerate to the profile speed. An example of this can be seen in Figure 6, which contains the airspeed profiles during the SADDE route for the slow-to-fast speed scheme with future CMS phraseology. The initial speed clearance was to "decrease speed to 220 until DEANO, then resume published speeds." The published speed restriction at DEANO was 280 knots. Crew 9 (dashed magenta line in Fig. 6) entered 220 knots into the FMS and expected the commanded speed to change to 280 knots when the aircraft approached DEANO. Once they realized that the commanded speed remained at 220 knots, they reverted to MCP Speed Intervention to accelerate to the profile speed of 280 knots.

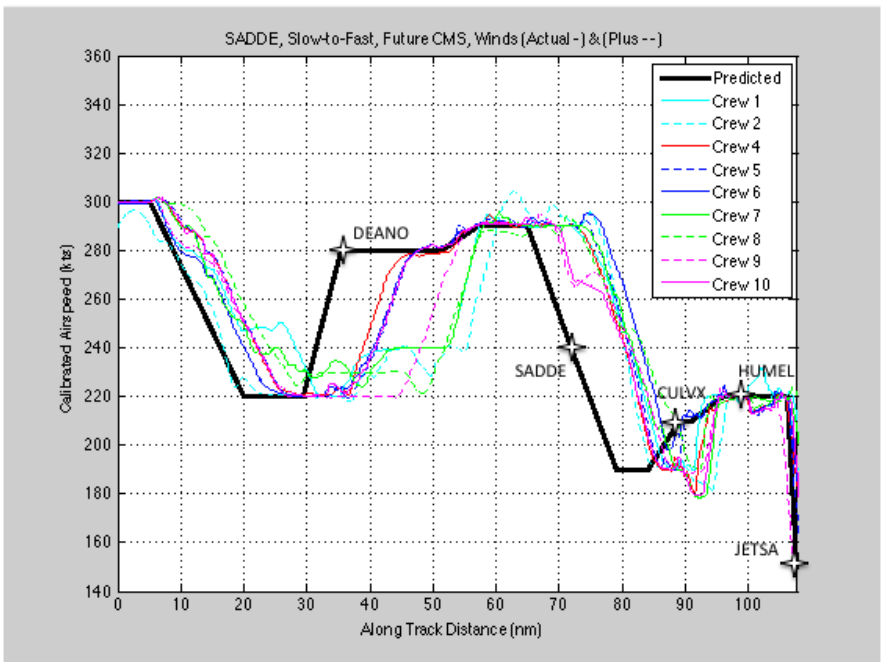

Figure 6. Airspeed Profiles (SADDE, Slow-to-Fast, Future CMS) 
Another issue that was encountered when crews waited until they reached the "until" waypoint before starting to resume to the published speeds, was that some crews resumed to the wrong speed. This is because once the waypoint was sequenced, the waypoint and the corresponding speed restriction would no longer appear in the LEGS page of the FMS. As a result, crews would have to refer to the charted procedure in order to determine what the profile speed should be. In several cases, crews resumed to the speed corresponding to the next speed restriction at a downstream waypoint. An example of this can been seen in Figure 6, where crews were supposed to resume to the profile speed of 280 knots upon reaching DEANO. Crews 1, 2, and 7 resumed to 240 knots (i.e., the speed restriction at SADDE) instead of 280 knots (i.e., the speed restriction at DEANO).

\section{B. Speed Transition Execution Strategies}

While interpretation of the current day phraseology clearances was not a factor, significant descent time variations were still encountered (especially when the aircraft was decelerating to a slower speed). Some of the contributing factors that led to this variation were the different strategies that were used to execute speed transitions. The strategic nature of the FMS can make tactical operations (such as speed changes) problematic, especially during OPDs where tradeoffs between speed and altitude must be constantly taken into consideration. When the aircraft is no longer being controlled along the computed vertical path, crews lose the benefits of having a strategically generated 4DT that optimizes performance while complying with constraints. These off-path operations have a tendency of decreasing situational awareness and increasing workload, since crews must now manage energy tradeoffs to ensure constraint compliance.

Crews employed different methods of using the automation to execute the current day speed clearances (as with the future CMS speed clearances discussed above). Most crews entered the commanded speed into the MCP and flew the descent in VNAV SPD (Fig. 7a) via MCP Speed Intervention. When a faster commanded speed was entered, the aircraft would increase its decent rate (and depart below the vertical path) in order to accelerate to the new commanded speed. Unless additional thrust was added to decrease the descent rate, the aircraft would eventually level off at the next altitude constraint until it crossed the corresponding waypoint. When a slower commanded speed was entered, the aircraft would decrease its rate of descent (and depart above the vertical path) in order to decelerate to the new commanded speed. Unless additional drag was added (by deploying speed brakes or flaps), the aircraft could violate subsequent altitude constraints.

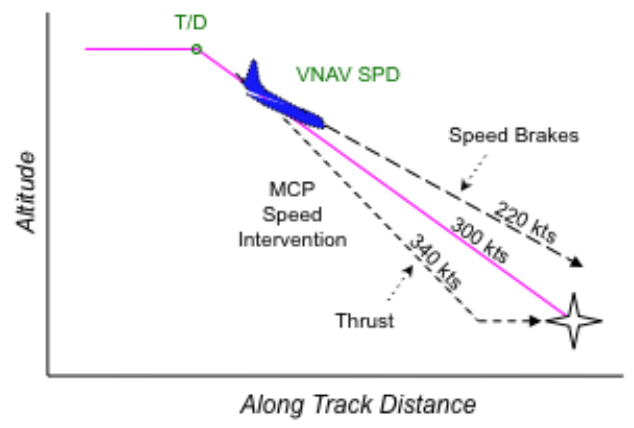

(a)

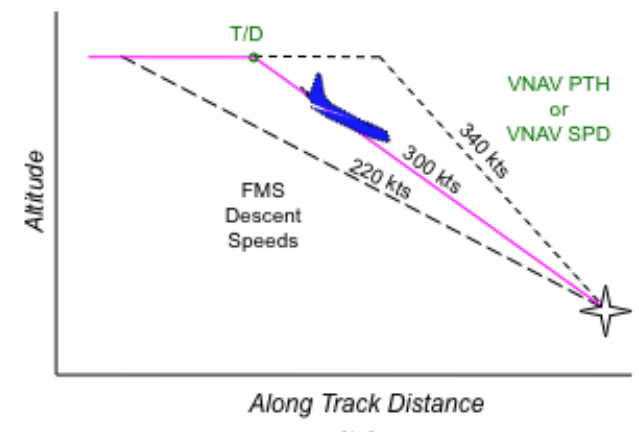

(b)

Figure 7. Speed Changes During OPDs

A few crews entered the commanded speed into the FMS and flew the recomputed vertical path in VNAV PTH (Fig. 7b). When a faster commanded speed was entered, the vertical path was recomputed above the aircraft. If the vertical path stayed close enough to the aircraft, it would stay in VNAV PTH and decrease its descent rate in order to recapture the vertical path from below. The airspeed would start to increase once the aircraft was flying the steeper vertical path. When a slower commanded speed was entered, the vertical path was recomputed below the aircraft. If the vertical path stayed close enough to the aircraft, the aircraft would stay in VNAV PTH and increase its descent rate in order to recapture the vertical path from above. The airspeed would start to decrease once the aircraft was flying the shallower vertical path.

Since the current day phraseology resulted in open-ended speed clearances (i.e., without a termination point), crews that entered the commanded speed into the FMS needed to prevent the FMS from automatically resuming profile speeds at downstream waypoints (unless another speed clearance was issued before that time). As a result, some crews modified or removed the speed restriction at the next waypoint (resulting in a recomputed vertical path). 
In general, crews that descended the aircraft in VNAV SPD tended to accelerate and/or decelerate faster than crews that descended the aircraft in VNAV PTH. An example of this can be seen in Figure 8, which contains the calibrated airspeed profiles during the SADDE route for the fast-to-slow speed scheme with current day phraseology. The initial speed clearance was to "increase speed to 340", followed by a second clearance to "reduce speed to 280", and then a third clearance to "reduce speed to 220". Crew 8 (solid green line in Fig. 8) accelerated to 340 knots in VNAV PTH and had the slowest rate of acceleration, and decelerated to 280 knots (primarily) in VNAV PTH and had the slowest rate of deceleration. Crews 8 and 9 (solid green and magenta lines in Fig. 8) decelerated to 220 knots (primarily) in VNAV PTH and had the slowest rates of deceleration.

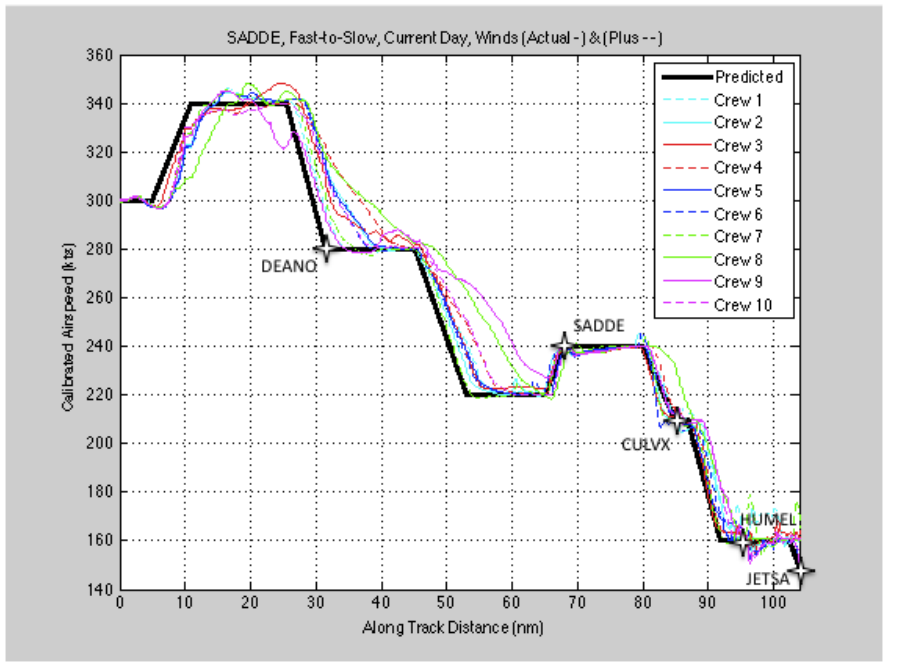

Figure 8. Airspeed Profiles (SADDE, Fast-to-Slow, Current Day)

Another factor that influenced descent speed variations was dependent upon how crews managed energy during the descent. Some crews entered the commanded speed into both the MCP and the FMS. While these crews descended in VNAV SPD (via MCP Speed Intervention), they could use the recomputed vertical path as a reference to determine if they needed to manipulate throttles or speed brakes in order to keep the aircraft close to the vertical path. An example of this can been seen in Figure 9, which contains the altitude profiles during the SADDE route for the fast-to-slow speed scheme with current day phraseology (that corresponds to the airspeed profiles in Fig. 8). While descending at 340 knots in VNAV SPD, crews 4 and 10 (dashed red and magenta lines in Fig. 9) added thrust to keep the aircraft closer to the vertical path (for energy efficiency). Meanwhile, the other crews that descended at 340 knots in VNAV SPD (i.e., crews 1, 2, 5-7, 9) had faster descent rates and ended up flying level at FL200 for several nautical miles prior to DEANO, allowing them to decelerate faster to 280 knots.

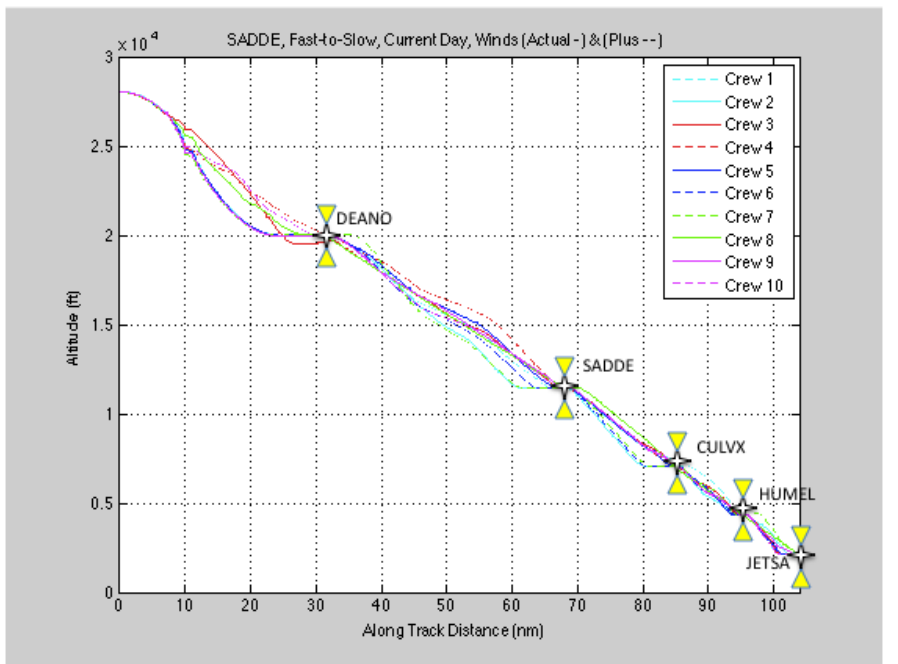

Figure 9. Altitude Profiles (SADDE, Fast-to-Slow, Current Day) 


\section{Altitude Constraint Compliance Strategies}

In general, most crews commented on the level of difficulty in descending fast enough to meet an altitude constraint while decelerating the aircraft to a slower commanded speed at the same time. Some crews (e.g., crew 8 in Fig. 6) traded speed for altitude by increasing the commanded speed (e.g., from 220 knots to 230 knots prior to DEANO) in order to increase the rate of descent while in VNAV SPD. A few crews reverted to flying non-FMS modes, such as vertical speed (or V/S), as a technique for increasing the rate of descent (e.g., crew 3 in Fig. 9 prior to DEANO) at the expense of speed.

One of the biggest challenges, when decelerating to a slower commanded speed during OPDs, was determining when speed brakes were necessary to achieve altitude constraints. Overall there were 7 instances of altitude violations where aircraft crossed waypoints at least $1000 \mathrm{ft}$ above the altitude constraint. An example of this can been seen in Figure 10, which contains the altitude profiles during the RIIVR route for the slow-to-fast speed scheme with future CMS phraseology. Crew 9 (dashed magenta line in Fig. 10) did not extend speed brakes soon enough to meet the altitude restriction at GRAMM. Crew 4 (solid red line in Fig. 10) elected to perform an early descent (i.e., Descend Now), which commanded the throttles to capture a very shallow (500 feet per minute) descent rate. However, since the crew executed the (220 knots) speed clearance via MCP Speed Intervention, the FMS stayed in VNAV SPD instead of transitioning to VNAV PTH when the aircraft intercepted the vertical path. As a result, the throttles were never commanded to idle.

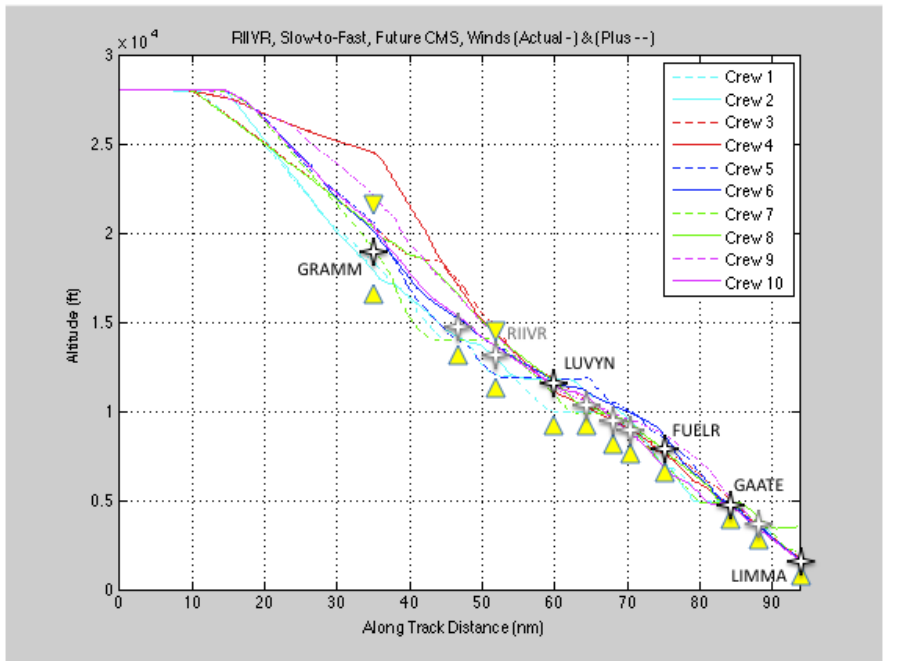

Figure 10. Altitude Profiles (RIIVR, Slow-to-Fast, Future CMS)

One method of determining whether or not the aircraft will achieve an altitude constraint is by looking at the "green arc" on the navigation display, which displays the distance it will take the aircraft to reach the altitude that has been entered into the MCP (i.e., MCP Altitude), given the aircraft's current descent rate. However, different carriers had different procedures for setting the MCP Altitude. Some carriers would set the MCP Altitude to the next altitude constraint, or to the AT OR ABOVE portion of a window constraint (to prevent the automation from descending the aircraft below that altitude). However, if the crew forgot to lower the MCP Altitude by the time the aircraft crossed the waypoint, the aircraft would be prevented from continuing its descent. Other carriers would set the MCP Altitude to the lowest altitude that the aircraft had been cleared for along the route.

In general, there were very few instances where crews flew below an altitude restriction. This is because the FMS provides protections against flying below an altitude constraint at a waypoint by automatically transitioning from VNAV SPD to VNAV PTH to level off (e.g., crews 1, 2, 5-7, 9 in Fig. 9 prior to DEANO). However, when a crew reverted to a non-FMS mode, with the MCP Altitude set below the altitude constraint, there was no automated protection that prevented the aircraft from flying below the altitude constraint. For example, crew 3 (solid red line) in Figure 9 flew approximately 500 feet below the FL200 altitude constraint at DEANO in V/S, before the crew switched modes to hold the current altitude (or ALT) in order to prevent the aircraft from descending further.

In cases where crews forgot to lower the MCP Altitude by the time the aircraft crossed the waypoint, the FMS would transition modes to capture and hold the MCP Altitude (or VNAV ALT). However, it sometimes took crews a while to notice that the aircraft was not descending. This was especially problematic when the aircraft was 
approaching the outer marker (e.g., crew 8 in Fig. 10 prior to LIMMA), since there was not sufficient time to compensate for the excess energy. This resulted in several high-energy approach and/or go-around situations.

\section{Mode and Energy State Awareness Issues}

In highly automated flight-decks, pilot actions are coupled with automated control of the aircraft. As a result, crews must be cognizant of the automation modes under which the aircraft is operating and understand the interaction between the modes of automation and pilot inputs. ${ }^{12}$ When the pitch-axis of the aircraft is controlling a path (i.e., path mode), the throttles and speed brakes are used to control the airspeed. Examples of this mode include VNAV PTH (i.e., flying the vertical path calculated by the FMS) and VNAV ALT (i.e., flying the MCP Altitude). When the pitch-axis of the aircraft is controlling a speed (i.e., speed mode), the throttles and speed brakes are used to control the climb or descent rate. An example of this mode is VNAV SPD (i.e., flying the airspeed in the FMS or via MCP Speed Intervention). However, during the descent phase of flight, VNAV SPD will switch from a speed mode to a path mode when necessary to prevent the aircraft from climbing during descent.

One of the questions investigated in this study was whether or not crews would be able to fly these OPDs while meeting large (twenty percent) speed deviations. While most crews were able to successfully fly the descents while complying with the speed clearances, there were a number of events that indicate potential mode and energy state awareness issues. These events included altitude restriction violations, airspeed excursions, and high-energy approach and/or go-around situations. Potential indicators leading up to these events included:

1) Speed brakes extended when throttles were not at idle

2) Speed brakes extended in speed mode when aircraft was below the vertical path

3) Throttles advanced in path mode when airspeed was greater than the commanded speed

4) Throttles retracted in path mode when airspeed was less than the commanded speed

Speed brakes extended when throttles were not at idle:

Crews often extended speed brakes while descending in a speed mode to increase the aircraft's descent rate to comply with altitude constraints (especially when the aircraft was decelerating to a slower commanded speed). In some cases, crews did not realize that the throttles were not at idle. This usually occurred when the automation had previously set the throttles to a non-idle position, thus restricting the aircraft's descent rate. This contributed to altitude constraint violations and high-energy approach and/or go-around situations.

Speed brakes extended in speed mode when aircraft was below the vertical path:

Crews occasionally extended speed brakes while descending in a path mode to increase the aircraft's deceleration rate (especially when the aircraft was decelerating to a slower commanded speed). In some cases, crews did not realize that the aircraft was in a speed mode (where the pitch-axis of the aircraft was controlling the deceleration rate). The extended speed brakes caused the aircraft to increase its descent rate, until the eventually leveling off in a path mode to prevent the aircraft from descending below the next altitude constraint. This resulted in an energy inefficient descent.

Throttles advanced in path mode when airspeed was greater than the commanded speed:

Crews occasionally advanced throttles while descending in a speed mode to decrease the aircraft's descent rate (especially when the aircraft was accelerating to a faster commanded speed). In some cases, when crews advanced the throttles too much and/or too quickly, the aircraft switched from a speed mode to a path mode to prevent the aircraft from climbing during descent. This caused the aircraft to gain airspeed, resulting in a high airspeed excursion. In two cases, the aircraft exceeded (or nearly exceeded) the maximum operating speed of the aircraft.

Throttles retracted in path mode when airspeed was less than the commanded speed:

In some cases, crews retracted throttles (against the throttle servos) while the aircraft was flying level at the MCP Altitude in a path mode (i.e., VNAV ALT). Pilot comments indicated that the crew was trying to descend (thinking the aircraft was in a speed mode). This caused the aircraft to lose airspeed, resulting in a low airspeed excursion.

\section{Conclusions and Future Research}

The primary focus of this study was to evaluate the potential impact of ground scheduling tools on crews' performance and procedures. Two of the underlying assumptions that were investigated in this study were: (1) crews would be able to fly these OPDs while meeting the large (twenty percent) speed deviations issued to them using existing automation; and (2) they could do it without any additional training. Although the study was exploratory in 
nature, four variables were manipulated: route constraints, winds, speed changes, and clearance phraseology. Despite flying the same scenarios with the same events and timing, there were significant variations in the time it took crews to fly the approaches. This variation is the product of a number of factors, and highlights potential difficulties for scheduling tools that would have to accommodate this amount of natural variation in descent times.

One of the major factors contributing to descent time variations when executing the future CMS phraseology was that crews interpreted and executed the conditional part of the clearance in different fashions. Furthermore, it was unclear whether or not some crews understood how to determine the profile speed that they were supposed to resume (since they appeared to use different approaches on different flights). In lieu of training, additional research will explore options for a special flight-manual bulletin that explains in further detail how to interpret the future CMS clearance.

Another significant factor contributing to descent time variations were the different strategies that crews used to execute speed transitions. In general, making speed changes when flying OPDs is problematic, since crews can no longer fly strategically generated 4DTs that optimize performance while complying with constraints. As a result, crews have to determine how to manage energy tradeoffs between speed and altitude. While the objective is not to introduce new flight-deck automation, it is possible that some relatively minor enhancements could address some of the human-automation interaction issues that were identified. The addition of predicted altitude information at waypoints will be assessed to determine if it provides sufficient energy awareness to assist crews in handle large speed changes more consistently. The option of having AT speed constraints in descent (in addition to AT OR BELOW speed constraints) will be assessed to determine if it provides sufficient FMS compatibility with future CMS clearances to enable closed 4DT operations for reduced descent time variations.

No conclusions could be reached in terms of the benefit of hard altitude constraints on the SADDE route, versus window altitude constraints on the RIIVR route. While the RIIVR route resulted in larger descent time variations, the SADDE route resulted in more altitude constraint violations. However, most of these violations occurred during the plus wind condition, which resulted in an additional tail wind that could have impacted the difficulty of achieving altitude constraint compliance.

\section{References}

${ }^{1}$ Walter, R., "Flight Management Systems," The Avionics Handbook, edited by Cary R. Spitzer, CRC Press LLC. 2001.

${ }^{2}$ Robinson III, J. E., 2011, “Air Traffic Management Technology Demonstration-1 (ATD-1): Interval Management-Terminal Area Precision Scheduling System Demonstration Description and Plan, Version 2.5," NASA Ames Research Center, CA, October 2011.

${ }^{3}$ Swenson, H., J. Thipphavong, A. Sadovsky, L. Chen, C. Sullivan, \& L. Martin, "Design and Evaluation of the Terminal Area Precision Scheduling and Spacing System," Proceedings of the Ninth USA/Europe Air Traffic Management Research and Development Seminar (ATM2011), Berlin, Germany, June 2011.

${ }^{4}$ Isaacson, D., J. Robinson III, H. Swenson, \& D. Denery, "A concept for robust, high density terminal air traffic operations," $10^{\text {th }}$ AIAA Aviation Technology, Integration, and Operations (ATIO) Conference, Fort Worth, TX, 2010.

${ }^{5}$ Prevôt, T., P. Lee, T. Callantine, J. Mercer, J. Homola, N. Smith, \& E. Palmer, "Human-in-the-Loop Simulation of NextGen Concepts in the Airspace Operations Laboratory," Proceedings of the AIAA Modeling and Simulation Technologies Conference, AIAA-2010-7609, Toronto, Ontario, 2010.

${ }^{6}$ Kupfer, M., T. Callantine, L. Martin, J. Mercer \& E. Palmer, "Controller support tools for schedule-based terminal-area operations," Proceedings of the Ninth USA/Europe Air Traffic Management Research and Development Seminar (ATM2011), Berlin, Germany, June 2011.

${ }^{7}$ Callantine, T., E. Palmer \& M. Kupfer, "Human-in-the-loop simulation of trajectory based terminal-area operations," $27^{\text {th }}$ International Congress of the Aeronautical Sciences (ICAS), Nice, France, 2010.

${ }^{8}$ Prevôt T., "How to compute a slot marker - calculation of Controller Managed Spacing tools for efficient descents with precision scheduling," Proceedings of the 31st Digital Avionics Systems Conference (DASC2012), Williamsburg, VA, October 2012 .

${ }^{9}$ Martin, L., S. Sharma, S. Lozito, J. Kaneshige, M. Hayashi, \& V. Dulchinos, "Flying Schedule-Matching Descents to Explore Flight Crews' Perceptions of their Load and Task Feasibility," 31st Digital Avionics Systems Conference (DASC), Williamsburg, VA, October 2012.

${ }^{10}$ Sullivan, B.T. \& P.A. Soukup, "The NASA 747-400 flight simulator: A national resource for aviation safety research," AIAA-96-3517-CP, American Institute of Aeronautics and Astronautics, San Diego, CA, July 1996, pp. $374-384$.

${ }^{11}$ Prevôt, T., P. Lee, T. Callantine, J. Mercer, J. Homola, N. Smith \& E. Palmer, "Human-in-the-loop evaluation of NextGen concepts in the Airspace Operations Laboratory," AIAA 2010-7609, American Institute of Aeronautics and Astronautics, Reston, VA, 2010.

${ }^{12}$ Commercial Aviation Safety Team, "Mode Awareness and Energy State Management Aspects of Flight Deck Automation," Safety Enhancement 30, Revision-5, Final Report, August 2008. 